\title{
Em Torno do Avigoramento dos Modernos Executivos
}

\section{Gilberto Freyre}

Sociólogo, escritor e professor universitário

Um processo social, tão atuante nos Estados Unidos como na Europa e noutras partes do mundo de hoje, vem, revolucionariamente ou evolucionariamente, fazendo declinar regimes predominantemente parlamentares e, ao mesmo tempo, grandemente dependentes de partidos apenas políticos e de ritos de democracia convencionalmente eleitoral; e fazendo emergir, ou ressurgir, sob coloridos novos, e sob várias formas, um poder ou um executivo político-administrativo como que sociologicamente monarquizado. Estamos diante de executivos limitados, em seu crescente poder, menos pela vontade predominante de maiorias parlamentares ou de maiorias maciçamente eleitorais, que por outros fatores: um deles, a força, também ascendente, de elites de assessores científicos, técnicos, culturais do tipo dos, nos dias do segundo Roosevelt - um dos pioneiros desse novo tipo de poder - denominados "brain trusts" nos Estados Unidos; dos Ministérios de Cultura e do de Informação, do atual tipo francês; dos assessores econômicos que constituem quase ministérios, e até superministérios além dos ministérios apenas políticos, em Repúblicas como a Federal da Alemanha - um dos quais passou, em momento crítico na vida alemã, dessa alta categoria à de líder político; e dos grupos de assessores, peritos em física nuclear e em astronáutica que, na União Soviética de hoje, detêm já notável participação no poder político-militar ali, desde Lenine, monarquizado em extremo, esse excesso, tendo perdurado intacto até Krutchev - que alguns estudiosos do assunto consideram já superior, sob alguns aspectos, ao do Partido Comunista e ao do chamado Exército Vermelho. Superiores 
como força de direção nacional ou imperial, inseparável da do monarca propriamente monárquico, em termos sociológicos, ali tão efetivo: mesmo agora, após Krutchev.

Fique claro que há modernas tendências, por um lado, para uma como que monarquização - monarquização como forma sociológica e não como figura ortodoxa de Direito Público - do poder executivo, tanto político como administrativo, e, por outro lado, para a sua personalização em chefes, carismático ou não, mas sempre pessoais, no exercício desse poder. Poder que os seus detentores exercem, identificando suas personalidades com a função e com o essencial das constantes e das aspirações da gente a que serve. Isto sem excluir-se a intelectualização e a tecnização de parte do mesmo poder, através de assessoramentos de crescente importância que, aliás, se façam sentir não só junto aos executivos assim dinamizados como junto a legislativos e judiciários igualmente necessitados de uma mais ampla informática.

O que se verifica, porém, é que esse assessoramento, através dos orientadores e consultores de maior ou menor influência junto a esses chefes, "monarquizados", de modernos executivos, fazendo-se sentir em assuntos científicos e técnicos de governo, de administração, de diplomacia - assuntos relacionados principalmente com o desenvolvimento e a segurança nacionais - empalidece distinções, outrora tão vivas, entre categorias políticas e não-políticas de poder. Se não destroem no poder político o que nele é essencialmente político, como poder decisivo e, portanto, máximo - o poder decisivo que tende a ser, agora, em alguns paises, sob aspecto sociologicamente monarquizado, além de personalizado, em vez de palidamente subordinado ao legislativo e de cinzentamente impessoal, tendem também a moderar paradoxalmente esse poder. Não, porém, ao ponto de reduzi-lo a puro poder superburocrático. Pois seu primado como poder de decisão é parte de sua como que monarquização.

Já vários políticos modernos, detentores de funções executivas, vêm agindo de acordo com assessores; intelectuais que representassem um novo poder, moderador ou orientador ou esclarecedor do apenas político. André Malraux, por exemplo, em suas relações com De Gaulle, que sirva de exemplo recente. Ao tomarem decisões aparentemente só políticas, ou só econômicas ou só intelectuais, mas na verdade, algumas delas, além 
de políticas ou politicoeconômicas ou politicomilitares ou politicoadministrativas, complexamente socioculturais, vários politicos modernos têm se valido de informes, orientações e inspirações de superassessores: de vários e não de um só. O Premier Harold Wilson - também ele, durante algum tempo, um a seu modo chefe "monárquico", ainda que Trabalhista, do Reino Unido, havendo quem considere um moderno Premier britânico, com o declínio do poder do Parlamento na Grã-Bretanha, relativamente mais "monárquico", no exercício de suas funções de chefia, do que o Presidente dos Estados Unidos, com relação ao Congresso - inclusive o Senado - teve a assessorá-lo, com outros homens de ciência, o sábio C. P. Snow, físico e humanista, do mesmo modo que De Gaulle se valeria do já citado Malraux; e na mesma época em que o Presidente Johnson, dos Estados Unidos, firmava-se, para sua política internacional, principalmente em orientações e informes de outro intelectual de grande porte, Walt Whitman Rostov, de quem é sucessor o Professor Henry Kissinger, já agora Secretário de Estado.

Todas estas modernas expressões de executivos vigorosos, assessorados, orientados, esclarecidos, informados por intelectuais - cientistas, sábios, técnicos e até escritores (o caso de Malraux) - de alto porte, se apresentam cada vez mais semelhantes, umas às outras, pela sua maneira de serem os chefes, chefes de Estado, de feitio sociologicamente monárquico, moderados no seu poder pela influência daqueles superassessores que, junto a tais "monarcas", representam o poder da inteligência. da ciência, do saber de crescente importância na transição do que no mundo de hoje é apenas moderno para o pósmoderno. Apenas - e este apenas é importante - maior e mais atuante é o corretivo a qualquer tendência, entre os modernos chefes de Estado, ao cesarismo clássico, à medida que cresce a importân. cia dos assessores desse tipo superior.

Em países onde as elites de consultores são elites prestigiosas - exceção feita da Rússia Soviética, onde somente as elites de físicos nucleares desfrutam desse prestígio - a participação de pensadores e cientistas sociais no poder político vem se fazendo sentir, junto com a de outros indivíduos superiores pela inteligência e pelo saber, em várias especialidades, de modo a impedir qualquer cesarismo absoluto, da parte do poder apenas político ou somente administrativo. Fenômeno que ocorre na própria União Soviética com a influência atual, sobre seus chefes políticos e militares, de cientistas físicos. 
Nada de resvalarmos no simplismo de considerarmos governos excepcionalmente investidos de funções como que monárquicas, na sua maneira sociológica de ser, não simples poderes executivos, mas poderes decisivos, que devessem ser sempre considerados "governos reacionários", isto é, detentores de grande poder político animados do exclusivo objetivo de contrariarem inovações, renovações, mudanças, revoluções. Através de alguns deles é que grandes reformas sociais, das chamadas progressivas e até revolucionárias, têm sido realizadas, ou estão sendo realizadas, em nossa época, para satisfação de populações nacionais numerosas. São populações, essas, nos países em desenvolvimento, bem mais desejosas de tais reformas do que de serem ajustadas a modelos suíços ou escandinavos ou ianques de democracia política em termos idealmente eleitorais ou idealmente parlamentares. Modelos, alguns deles, grandemente prejudicados por aquela corrução políticoadministrativa de que o Brasil, com a tradição, que guarda, do poder monárquico no seu sentido literal, tem, nessa tradição, forte reserva contra o perigo de resvalar, sem corretivos, em extremos que degradariam, à sombra do avigoramento dos executivos, sua política e sua administração.

Se o triunfo de um regime que se intitule "progressista" é o "pressuposto para compreender, em extensão considerável, os objetivos de desenvolvimento", tal como hoje se compreende desenvolvimento - tecnológico, econômico, social - assunto que vem versado numa das páginas do meu recém-aparecido: Além do Apenas Moderno - a que se refere o Professor Richard Loewenthal, em recente e notável estudo de Sociologia da Política: as conferências que proferiu em 1962 na Universidade Livre de Berlim e que constam, no original alemão, da obra coletiva Die Demokratie in Wander Gesseischaft (1962) - então temos que admitir a correlação entre os regimes de chefia pessoal e sociologicamente "monárquica", que sejam também atentos aos problemas militares da época que atravessamos - e não liricamente pacifistas por purismo civilista - e o êxito alcançado por esses regimes através de programas nacionais de desenvolvimento em prazo relativamente rápido. Foi o caso, pioneiro, em nossa época, da Turquia; e vem sendo o caso da lugoslávia, com o Presidente Tito. O caso do próprio Egito, com o Presidente Nasser. O caso do México, com o regime de "partido único", que ali domina. Regimes que seria simplismo classificar de totalitários à maneira dos de Mussolini e de Hitler e mesmo do da União Soviética quando dominada por um Lenine, 
por um Stalin, com Krutchev tendo sido antes um tanto "principe", no moderno sentido sociológico da expressão, dado por de Jouvenel, do que um puro ditador absoluto. Pois são regimes que correspondem à definição de "principado" que Bertrand de Jouvenel oferece, em ensaio, também notável, de Sociologia da Política, aparecido no $n .^{\circ} 4$, de 1964, de Revue Française de Science Politique, da "monarquia" em sua forma moderna como poder. Poder pessoal, sim, porém regularizado: o tipo de poder estudado em 1961 por Benjamin Akzin, em Futuribles e citado por de Jouvenel naquele seu excelente ensaio. Num e noutra - no "principado" e na "monarquia" definidos tão-somente sociologicamente - as elites intelectuais, científicas, técnicas, as elites de consultores de que se cerca todo "principe" moderno que seja sociologicamente príncipe, para delas, elites orientadoras, depender, em vários assuntos, até certo ponto, e, em alguns desses assuntos, quase de todo, ou mesmo de todo, são consideradas pelos politicólogos e pelos sociólogos modernos, corretivos ao que poderia tender ao cesarismo clássico entre os modernos chefes de Estado que exercem monárquica e, em alguns casos, pessoalmente - como foram o caso do segundo Roosevelt, nos Estados Unidos, e o de De Gaulle, na França o poder como "principes" no sentido Jouveneliano.

Numa época em que, dos próprios militares de um novo tipo - e sobre militares de um novo tipo já há estudos sociológicos idôneos - mais preocupados com problemas nacionais, alguns se mostram como que receosos de quanto, em presenças militares no trato desses problemas, possa parecer militarismo aos olhos de suas comunidades - certo como é que o moderno conceito de segurança, estudado brilhantemente no Brasil pelo Professor Mário Pessoa, é, em parte considerável, extramilitar - é preciso que se acentue a crescente superação, em vários setores, da antítese militarismo-civilismo. O Plano Marshall foi bem a primeira grande evidência dessa superação. $O$ governo De Gaulle, na França, foi outra. A intervenção das Forças Armadas em 1964 na vida política do Brasil foi — ou está sendo - ainda outra.

A expressão criada por Hugh Seton-Watson, no livro Neither War nor Peace - Seton-Watson é também autor do excelente estudo "Twentieth Century Revolutions", publicado em 1951, no Political Quarterly, XXII/3 - para caracterizar um novo tipo de militar que circunstâncias especialíssimas de uma época, para ele, nem de paz, nem de guerra, porém mista, como é a 
nossa, tornou necessário, em vários países, é significativa, embora para alguns de nós, não de todo satisfatória: "intelectuais em uniforme". Seriam intelectuais no sentido, não de serem literatos ou beletristas, acadêmicos ou eruditos só de gabinete, mas expressões daquela inteligência analítica, daquela imaginação científica, daqueles saberes mais concretos do que abstratos, que precisam, atualmente mais do que nunca, de estarem a serviço da direção das forças militares de uma nação ou de um conjunto de nações nas áreas em que essa direção deixa de corresponder ao controle de simples - se é que podem ser considerados simples - recursos tecnológicos de segurança nacional ou supranacional pelas armas para se relacionarem com aspectos outros - econômicos, sociais, culturais e não apenas políticos e diplomáticos - daquele tipo novo de segurança. $\mathrm{Pa}$ lavra, essa - segurança - que tem um sentido atualíssimo e, repita-se, em grande parte, extramilitar, a dinamizá-la de tal maneira que é como se fosse uma palavra nascida de novo nos nossos dias. Não se trata da arcaica segurança, estática e simplesmente militar, mas de outra: dinâmica e complexa. Precisamos, em Sociologia, como noutras ciências modernas, considerar a semântica: os significados novos que estão tomando palavras clássicas. Segurança é uma dessas palavras.

Monarquização destaque-se de novo que é outra. Quando agora se fala em Sociologia da Política, de "monarquização do poder", precisamos nos esquecer do sentido clássico, histórico, substancial, de poder monárquico; e atentarmos apenas na sua forma sociológica. Na sua pura forma sociológica.

A "monarquização do poder" hoje ocorre tanto na Europa como no México, em novas repúblicas africanas e orientais e nos próprios Estados Unidos, com o novo sentido que ali se está atribuindo ao poder presidencial. Ocorre - especifique-se na África, onde as primeiras tentativas de seguirem os novos Estados-nações modelos franceses e britânicos de governo republicano parlamentar por assembléias, através de eleições proclamadas como democráticas, se sucedem experimentos de novos tipos de chefia dos mesmos Estados e todos eles, ou quase todos, sociologicamente monarquizados e personalizados, em vez de despersonalizado o exercício do poder político. Acentue-se, considerando-se a importância da semântica, neste como noutros casos, que é um processo de instauração de tipos de governo estruturalmente novo e não de restauração dos antigos tipos monárquicos tanto nas suas substâncias como nas suas 
formas clássicas ligadas a essas substâncias. Trata-se tão-somente de "monarquização do poder" como forma: forma sociológica. Forma sociológica de poder político a serviço da comunidade; sensível às suas necessidades e às suas aspirações; flexível, ágil, por vezes imediata, no atendimento dessas solicitações; sempre atenta a tendências, coletivas ou de subgrupos, dentro de todos nacionais, que inovem com relação a constantes: constantes sempre merecedoras do máximo de atenção da parte de governantes pelo que revelará do que, no ethos dos governados, é ânimo, atitude, ou mesmo inércia: daquelas inércias já há sociólogos que sustentam serem, algumas, valiosas. Mais: é passado do denominado útil que uma nação precisa de valorizar, dele separando o inútil. O que, sendo exato, mostra quanto um conjunto nacional precisa de estar sempre em atitude de auto-análise; de autodescobrimento; de autoredescobrimento; de pesquisa de suas fontes e de suas tendências, de suas aspirações e de suas inclinações. Atitude que precisa de ser não só a dos modernos Executivos como a dos também em processo de dinamização Poderes Legislativo e Judiciário.

O Professor Loewenthal comenta, a propósito dos chamados "intelectuais em uniforme" - para voltarmos a este atualissimo assunto: a presença do militar intelectualizado no melhor sentido da expressão, nunca no de intelectualismo teórico, abstrato ou aliteratado, nos governos nacionais e em entendimen. tos transnacionais ou internacionais - que movimentos revolucionários de que têm participado decisivamente esses por ele denominados "intelectuais em uniforme" é que têm, não defendido os chamados interesses estabelecidos, ou o chamado statu quo, ou as classes intituladas conservadoras, porém derrubado redutos de "parlamentarismo oligárquico" - a expressão é do sociólogo europeu - tendo sido esta, em vários casos, em países islâmicos e latinoamericanos, a forma pela qual têm chegado ao poder movimentos revolucionários de caráter nacionalista "com extremos programas de desenvolvimento". Desenvolvimento ou modernização - inclusive a econômica e socialmente democratizante - como foi, na Turquia, a obra realizada por um movimento revolucionário de que participaram decisivamente elementos militares jovens; e cuja chefia tomou a forma sociológica de poder monarquizado e, ao mesmo tempo, personalizado. Veja-se, sobre o assunto, o estudo de Dankwart A. Ruston, "The Army and the Founding of the Turkish Republic", publicado em World Politics, XI/4, 1959. 
E já que estamos nos referindo à crescente "monarquização do poder executivo", no Oriente assim como no Ocidente - onde entraram em crise tanto o parlamentarismo britânico, nas suas expressões convencionais, como o francês, acentuando-se dia a dia a tendência, nos próprios Estados Unidos, para - Congresso ser menos assembléia, pura e simples, do que atuante, como poder legislativo, através de comissões técnicas assessoradas, várias delas, por cientistas sociais e não apenas por economistas e juristas; já que estamos também nos referindo à crescente tendência para as populações nacionais de hoje, sobretudo as das áreas denominadas subdesenvolvidas, reclamarem reformas sociais, econômicas, tecnológicas, desinteressando-se da democracia política na sua forma mecanicamente eleitoral, tão suscetível de corrução por meios plutocráticos ou de degradação por meios demagógicos - é oportuno lembrarmos aos atuais detentores do poder nacional no Brasil as palavras sábias de Dom João VI ao seu filho, o então regente Dom Pedro: "Antes que algum aventureiro, etc".

Antes que a "monarquização" do poder executivo no Brasil venha a se acentuar - sem que implique no desaparecimento de um legislativo também atuante, ao lado de um igualmente vigilante judiciário - por elementos menos idôneos, que se tornem usurpadores desse poder; antes de que as reformas sociais, econômicas, tecnológicas, que ainda nos falta realizar, sejam realizadas por meios menos ajustados às constantes nacionais de ethos e de cultura por detentores do poder, a seu modo monarquizados, mas deficientes no assessoramento intelectual, científico, técnico e na vigilância ética de que necessitam; antes de se verificarem essas e outras inconveniências e até desgraças - que os atuais dirigentes brasileiros, colocados em responsabilidades de comando nacional em conseqüência de um movimento revolucionário de opinião apoiado decisivamente pelas Forças Armadas, como foi o de 31 de março de 1964, as saibam evitar, em momento justo.

A importância que os atuais homens de governo já dispensem a superassessores, a pesquisadores, a analistas da chamada "realidade nacional", sem ter atingido toda a desejável amplitude, revela que o executivo está se avigorando, no Brasil como noutros países desenvolvidos e em desenvolvimento, com o corretivo de assessoramentos idôneos a possíveis arbítrios. Situo o Brasil entre aqueles países nos quais à chamada "monarquização do poder" se juntam assessoramentos de alto nível 
- de técnicos, de cientistas, de intelectuais especializados em saberes de importância social - capazes de esclarecer e orientar chefes, aos quais é evidente que toca a responsabilidade política das decisões. Decisões, porém, à base de informações, de orientações, de inspirações de assessores que, mestres de vários saberes, sejam colaboradores valiosos dos seus chefes.

Ninguém hoje pensa no que De Gaulle foi como chefe de um moderno tipo sociologicamente monárquico de poder político nacional sem pensar num André Malraux; num Presidente Johnson, sem pensar num Rostov, seu assessor genial; num Premier Wilson - por algum tempo Premier Trabalhista do Reino Unido - sem pensar em C. P. Snow; no atual Presidente dos Estados Unidos, sem pensar em Henry Kissinger. E, com relação aos três últimos Presidentes monarquizados, entre nós, num Roberto Campos, num Delfim Neto, num Mario Gibson Barboza. Isto para recordarmos apenas os mais conhecidos ou os mais eminentes desses assessores: esquecendo-nos das muitas "eminences grises"; dos Freis Joses mais cinzentos; dos sábios que silenciosamente, obscuramente, fornecem a "monarcas" modernos os elementos de decisão sobre os quais eles vêm agindo, não arbitrariamente, porém, quanto possível, objetivamente e, em alguns casos, até cientificamente - embora certas intuições nunca sejam desprezíveis quando vêm do mais profundo de vivências nacionais através, em alguns casos, de puros ou quase puros poetas ou artistas capazes de interpretações geniais do que é nacional num Estado-Nação. Para agirem não demagogicamente e sim, no melhor sentido da expressão, democraticamente, isto é, considerando sempre os interesses gerais da população e recolhendo-se, dessa população, sugestões à base de várias experiências ou situaçõ̃es de grupos ou subgrupos, dentre os que constituem o conjunto nacional, os modernos chefes de executivos nacionais precisam de assessores deste tipo especialíssimo: os que lhes tragam informes desse gênero das próprias fontes folclóricas. Informes e sugestões.

Pois eles precisam de sugestões que se façam sentir, não sob a simples pressão, junto a eles, homem governo, de ideologias ou de programas por mais merecedores de atenção, de partidos apenas políticos; nem sob o clamor de multidões dirigidas por agitadores apenas retóricos; nem sob imposições de órgãos de imprensa a serviço, por vezes, de grupos econômicos ou expressões de interesses privados contrários, - em 
alguns casos - aos gerais, mas que procedam de energias e de atividades nacionais que ultrapassem paixões ou interesses perturbadores dos interesses gerais e que, mesmo quando de origens modestas, precisam de ser ouvidas e, por vezes, consideradas. Trata-se de um processo eminentemente democrático de ligação de um moderno poder monarquizado com a comunidade nacional a que procure servir: comunidade constituída por grupos e subgrupos os mais diversos merecedores de ser ouvidos.

O Estado moderno, em que o poder seja sociologicamente monárquico, está, por isto mesmo, antes obrigado que desobrigado da responsabilidade de comunicar-se constantemente, por todos os meios atuais de informação, - aqui entra a importância da informática, em geral, quer das pesquisas psicosociais, sócioeconômicas, socioculturais, históricosociais, antropológicas, folclóricas, em particular - com os governados. O moderno chefe sociologicamente monarquizado de Estado não é apenas um chefe constantemente a informar-se sobre os governados. Ele é também importantíssimo como um superinformante; como um transmissor máximo de informações de interesse nacional; como um orientador da população nacional à base de informações idôneas, honestas, exatas.

Uma das revoluções modernas tecnológicas de maior repercussão sociológica e psicológica no setor das relações entre governos e governados é precisamente esta: a que torna o chefe de governo uma figura deficiente ou inatual se Ihe faltam ânimo e qualidades de superinformante da comunidade que governa. O moderno chefe de governo, queira ou não queira, precisa de se dispor a realizar, até certo ponto, o dito atribuído ao rei francês: "L'Etat c'est moi". Ele precisa de se fazer ouvir, em momentos justos, nos rádios, de ser fotografado nos jornais e nas revistas, de aparecer nas televisões, como a encarnação mesma do Estado que chefia. É o que esperam dele os modernos governados, seja na Europa, seja na Africa, seja nos Estados Unidos, seja no Oriente, seja na América do Sul ou na do Norte. É certo que na União Soviética faz-se atualmente sério esforço - parece que não de todo bem sucedido no sentido de contrariar-se essa tendência e de impedir-se a idealização, pelo seu povo, tradicionalmente inclinado a canonizar os líderes a que mais se afeiçoa, de um novo Pedro o Grande ou de um novo Lenine ou de um novo Stalin ou de um novo Krutchev. O governo seria cinzentamente burocrático ao 
mesmo tempo que secretamente supraditatorial; e nada - é a teoria neosoviética que o diz - personalizado. Será vitorioso esse esforço contra o pendor russo para o chamado "culto do herói" sob forma quase devocional ou mística? Provavelmente não. De qualquer modo é um experimento político-sociológico demasiadamente novo para ter validade cientificamente sociológica ou política: uma espécie de remédio novo, daqueles que os médicos se recusam a consagrar enquanto os resultados práticos de sua aplicação não se afirmem por um prazo cientificamente válido. Prazo - reconheça-se - difícil de ser determinado, tratando-se de experimentos que não são de laboratório mas de céu aberto.

Como difícil de ser previsto de modo exato, no plano científico, é o tipo de indivíduo que, sem ser precisamente carismático, corresponda, para o exercício de poder monarquizado, ao que do detentor de um poder assim forte espera a maioria da sua gente. De Gaulle parece ter chegado a satisfazer essa expectativa da parte dos franceses modernos: da maioria deles. A gente britânica, desde Winston Churchill, se mostra um tanto desencantada de governantes capazes de ser líderes monarquizados - no sentido sociológico - no exercício das funções de Primeiro Ministro de Sua Majestade, sem deixarem de todo de parecer ortodoxamente parlamentares. Entretanto, a atual crise britânica está sendo, ao que parece, vencida, pela sua nova liderança que sendo Conservadora tem, muito britanicamente, qualquer coisa de vanguardista.

Há fisionomias de todo não-monárquicas do ponto de vista da forma sociológica de detenção do poder por um indivíduo: forma hoje ressurgente de governo - quer de Estado, quer de empresas, de institutos, de universidades: quer na Europa, quer noutras partes do mundo. Parece ter sido esta a grande deficiência de Sir Stafford Cripps, quando Primeiro Ministro do Reino, em situação de ter alcançado grandes vitórias para a causa Trabalhista encarnada num "Welfare State" cuja mística substituísse a do então em crise Império Britânico. Faltou-Ihe, entretanto, a ação e vigor sociologicamente monárquico como à personalidade lhe faltou carisma. O carisma não é, entretanto, para ser considerado essencial ao moderno chefe de executivo vigoroso. Konrad Adenauer não o possuía e foi um chefe de executivo político de um tipo eficientemente renovador. 
O poder sociologicamente monárquico, quer seja na direção de Estado, quer de instituição outra, complexa - como igrejas, universidades, institutos - exige - acentue-se mais uma vez - um maior uso pelos detentores do poder político ou institucional, em modernas sociedades ou organizações, dos meios mais avançados de informação - de informática até - e de comunicação com o público. Exige - repita-se - dos como que monarcas que, através de televisões, rádios, fotografias, inspirem, em momentos - repita-se - justos, às populações ou aos grupos sob seu comando, o máximo de confiança. Isto, sobretudo: confiança.

Mas o que eles, modernos chefes de Estado sociologicamente monárquicos, dizem para o público precisa de conter orientações e inspirações - acentue-se, além de informes, que Ihe venham, em parte, de assessores suficientemente idôneos, entre os quais pensadores e cientistas sociais. Um dos modernos destinos de quantos se preparam em Ciências Sociais é o de assessores e consultores, de detentores do poder político ou de equivalente do poder político. É preciso que haja articulação entre os dois: os chefes que inspirem confiança e aqueles assessores e consultores, em assuntos sociais, em assuntos físicos, em assuntos técnicos de várias espécies, que sendo assessores, consultores, orientadores da confiança de seus chefes, sejam também homens de pensamento, de imaginação criadora e de estudo nos quais os demais possam confiar: confiar na sua ciência, no seu saber, na sua filosofia, na sua poesia, até, de colaboradores essenciais de chefes nacionais capazes de ser executivos ao mesmo tempo revolucionários e conservadores. Monarcas aos quais não falte aquele equilíbrio, aquela sabedoria de contemporização, aquele senso de oportunidade, aquele misto de suavidade e de energia dos dirigentes verdadeiramente capazes de dirigir repúblicas, enriquecidos pelo saber e pela inteligência dos assessores.

Numa época de superpotências dirigidas por superpotentes executivos, com o auxílio de supertécnicas, seria ingenuidade que Estados-Nações a caminho da condição de potências, como é o Brasil de hoje se deixassem desviar de seus destinos, fazendo-se frouxas, incertas e ingênuas democracias eleitorais e parlamentares de um tipo convencionalmente arcaico - pois os legislativos estão em fase de transformação - numa repulsa inoportuna aos executivos vigorosos nas suas atuações e realizações de caráter quer político, quer administrativo, além é 
claro, de asperamente honestos: de intolerantes, de negocistas e de negociatas; de fechados à advocacia administrativa, seja qual for o seu aspecto ou o seu disfarce. E que, com o auxílio de intelectuais, cientistas, técnicos, sejam governos e administrações assessoradas por grandes inteligências.

Um paradoxo do processo revolucionário que atualmente nos envolve e que traz até nós o futuro ou a ele nos leva de modo por vezes aparentemente mágico é que as aparentes potências conservadoras são hoje aquelas de onde estão a emergir algumas das idéias de reorganização administrativa e de relações do Estado com economias, mais revolucionárias. $A$ intelectualização dos serviços públicos na França, através da Escola de Administração Nacional - rival agora da Escola Normal Superior, da Politécnica e da Sorbonne - é revolucionária. Revolucionária é a intelectualização das direções das Forças Armadas nos Estados Unidos que desde Marshall, Ministro das Relações Exteriores, colaboram extramilitarmente com a orientação da política internacional seguida pelos Presidentes da Grande República. Situação a que se assemelha, no essencial, a da participação de militares, no Brasil, em postos de responsabilidade nacional extramilitar.

As aparentes potências revolucionárias como a União Soviética e como, até certo ponto, a China Comunista, de tão empenhadas em se consolidarem como potências militares e industriais, rivais das nações mais antigas nesses primados, mostram-se, paradoxalmente, conservadoras e até, por vezes, reacionárias em seus sistemas administrativos; e nas relações dos seus tipos de Estado totalitário com as populações e, dentro das populações nacionais, com os próprios operariados. Ao ethos do brasileiro parecem repugnantes as formas rigidamente totalitárias de governo. Mas não lhe repugna, segundo boas evidências, um presidencialismo que permita à nação em desenvolvimento enfrentar de modo incisivo problemas de transição social, com esse poder político executivo apto a intervir, em momentos justos, contra abusos de poderes econômicos e a favor da gente menos capaz de defender-se dessa espécie de abusos, quer quando subnacionais, quer quando antinacionais. Pois não se acha à vista do futurólogo um mundo organizado de tal modo sobre bases internacionais ou de tal maneira em correspondência com idéias supranacionais que a sociedade brasileira possa dar-se ao luxo de deixar de pensar em termos nacionais de economia, de política, de cultura. 
Note-sè que, além dos líderes políticos, empresários, industriais, líderes operários, líderes religiosos vêm sendo, entre nós, crescentemente intelectualizados, sem que a sua intelectualizaçạ̃o signifique seu distanciamento de problemas concretos e de realidades imediatas. Essa intelectualização de atividades denominadas práticas é provável que, no Brasil, se acentue nos próximos decênios. Estamos vivendo dias de intensas expressões, em vários setores, de um processo revolucionário de transição cuja intensidade e cuja extensão se apresentam acompanhadas de grandes e rápidas mudanças de caráter não só sociocultural como psicosocial e psicocultural, em conseqüência de aplicações de ciência à tecnologia e da tecnologia à vida. Vários os exemplos: a automatização, o aumento de média de vida, o aumento de tempo livre. O lazer com seu desafio à imaginação dos novos líderes do Brasil como de outros países em desenvolvimento.

São formas novas de vivência e de convivência brasileiras à espera de novos motivos de vida que, juntando-se a alguns dos antigos, terão que vir, não de técnicos nem sequer de cientistas apenas mas também dos pensadores, dos poetas, dos místicos, dos artistas, dos intelectuais de tipo menos realista; e também da atualização de heranças coletivas, mágicas, míticas, religiosas, guardadas pelos rústicos. Caminhamos para uma crescente intelectualização, direta e através de assessores, de lideranças que sejam renovadoras, no exercício tanto de funções legislativas e judiciárias, como, principalmente, de executivas. Mas sem que a essa intelectualização venha a faltar a inspiração dessas outras fontes de energia nacional, também elas necessárias ao avigoramento dos executivos com que as nações modernas enfrentam problemas de governo e de administração. 